ORIGINAL ARTICLE

\title{
Recurrent early childhood injuries among disadvantaged children in primary care settings
}

\section{P A Braun, B L Beaty, C DiGuiseppi, J F Steiner}

Injury Prevention 2005;11:251-255. doi: 10.1136/ip.2004.006510

See end of article for authors' affiliations

.....................

Correspondence to: Dr P A Braun, Denver Health, 501 28th Street, Denver, CO 80205, USA; patricia.braun@uchsc.edu

Accepted

19 February 2005
Objective: To examine differences in social risk factors and health care use between young children with and without recurrent injuries.

Design: Retrospective cohort study using administrative claims and medical records. Children with no, one, or more than one injury were compared.

Setting: Integrated public healthcare system.

Subjects: All children born at Denver Health Medical Center (DHMC) in 1993 who continued care there beyond 15 months of age. Children were followed to 36 months.

Outcome measures: Sociodemographic information, service use, injury episodes, cause of injury, and social risk factors.

Results: 371 injury episodes occurred among 817 children. In the study cohort, $7 \%$ had $>1$ injury episode, $26 \%$ had one injury, and $67 \%$ had none. Among children with $>1$ injury episode, $78 \%$ had at least one social risk factor compared with $63 \%$ of children with one injury and $52 \%$ of children with none $(p<0.0001)$. Risk factors for $>1$ injury included maternal substance abuse $(p=0.0003)$, maternal age under 18 years $(p=0.04)$, a primary caregiver who was single $(p<0.0001)$ or mentally ill $(p=0.03)$, and a history of family violence $(p=0.01)$. Multiple injury episodes were associated with increased non-injury service use, including primary care visits $(p<0.0001)$, emergency department visits $(p<0.0001)$, and total non-injury encounters $(p<0.0001)$.

Conclusions: Children with recurrent injury were more likely to have social risk factors, and used DHMC more frequently, than children with one or no injuries. Children with risk factors for recurrent injury can be identified and injury prevention counseling can be delivered to their families at their multiple visits to the system. njuries are the leading cause of death in childhood after the first year of life in the United States ${ }^{1}$ and account for 600000 hospitalizations, 10 million emergency department visits, ${ }^{2}$ and an estimated 10 million primary care office visits annually. ${ }^{3}$

Many studies have identified family life events or social stresses as factors that increase a child's risk for injury occurrence. These studies have found that young children from families with lower socioeconomic status, including lower median income, less education, and more unemployment, are at increased risk for injuries resulting in emergency department visits, hospitalization, or death. ${ }^{4-7}$ Having had a previous injury also puts a child at increased risk for another injury. ${ }^{8}$ Whether social risk interacts with risk associated with a previous injury has not been established. In addition, families of frequently injured children may differ in their patterns of healthcare use. One study found that children who were high users of medical care in a prepaid group practice had a higher risk of treated injuries. ${ }^{9}$ Some injuries might be prevented in children at risk for recurrent injuries by identifying their characteristics and social risk factors and targeting services toward them and their caregivers. A greater number of visits offers extra opportunities to intervene to prevent further injuries.

We hypothesized that young children who sought care for injuries would have more social risk factors, and that this relation would be most pronounced in those with multiple injury episodes. We also examined patterns of healthcare use to evaluate its relation with risk of injury recurrence.

\section{METHODS}

\section{Study setting}

We conducted our study within Denver Health Medical Center (DHMC), an integrated healthcare system comprising one hospital and 12 federally qualified community health centers. Patients seen in DHMC could seek healthcare services from other institutions in the area, but their lack of insurance limited this access.

We retrospectively identified all children born in DHMC between 1 January and 31 December 1993 who had one or more subsequent outpatient or inpatient encounters in the system before their third birthday and at least one encounter after 15 months of age. We only included children who had an encounter after 15 months in order to ensure that the children remained in the DHMC system. We excluded children with chronic health conditions, as defined by the National Association of Children's Hospitals, ${ }^{10}$ because their use of services could be determined largely by their chronic conditions. An experienced nurse reviewer abstracted the medical records of all eligible children who had one or more DHMC hospitalizations (in order to have sufficient numbers of hospitalized children for statistical analysis). Because of resource limitations, a random sample of the remaining cohort who were not hospitalized was selected using the random number function in SAS software, aiming for a ratio of non-hospitalized to hospitalized of approximately $4: 1$. The same reviewer abstracted the records of the children in this

Abbreviations: DHMC, Denver Health Medical Centre; TCH, The Children's Hospital. 


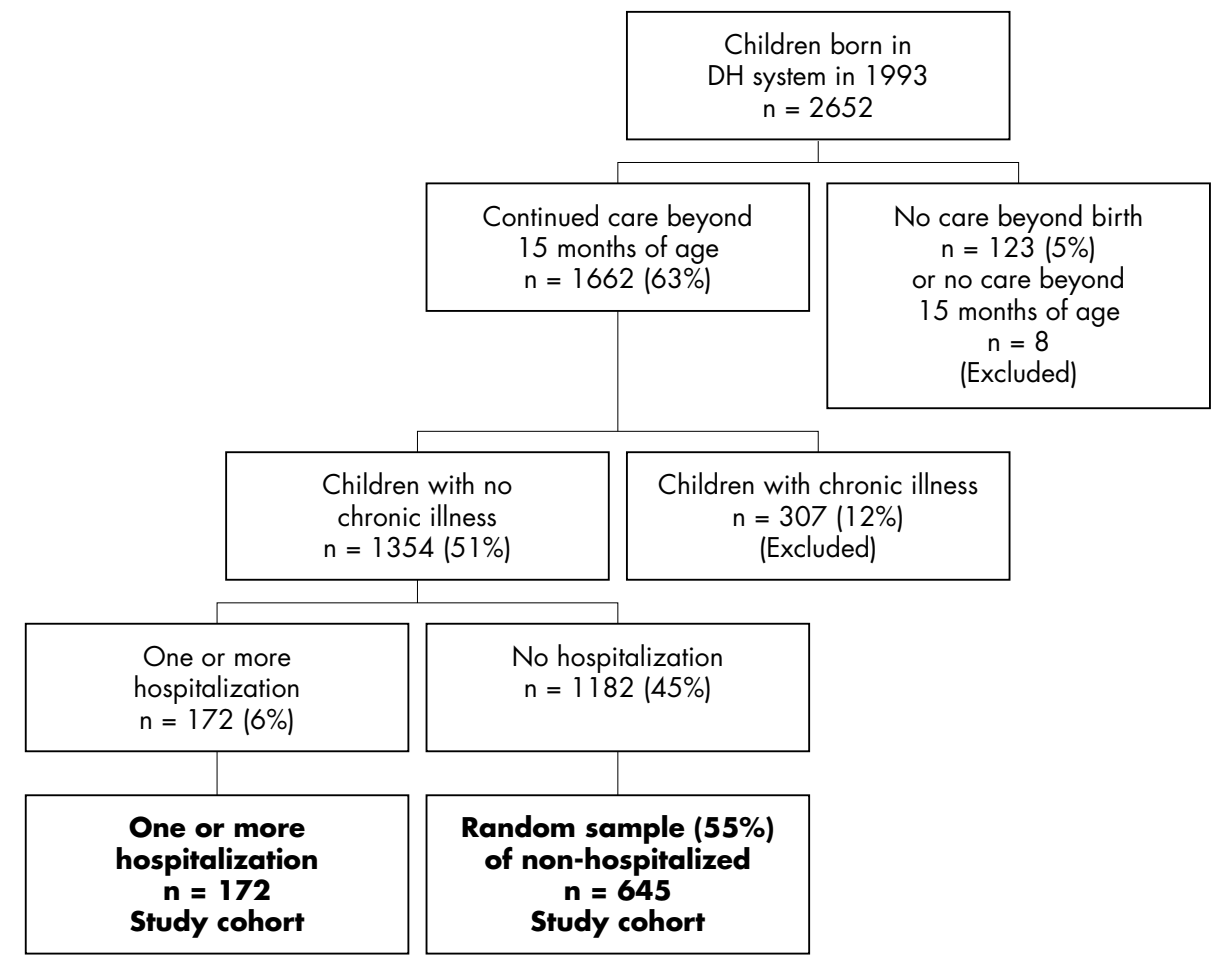

Figure 1 Study cohort.

sample. For the children included in the cohort, the reviewer extracted data on all visits from 0-36 months of age.

\section{Study measures}

From the DHMC administrative claims database, we extracted demographic, insurance, and utilization data. The reason for the visit and presence of social risk factors were abstracted from medical charts. These data were collected on all injury and non-injury related DHMC visits that occurred between 0 and 36 months of age for each participant. The forms used to record newborn and well child visits at DHMC are standardized and specifically ask about social risk factors, including maternal substance abuse, referral to child protection/social services, mother under 18 years of age at child's birth, history of family violence, child abuse or neglect, caregiver with mental illness, incarcerated parent, single parent, homelessness, caregiver receipt of government income support, and referral to a clinic social worker, case manager, or early intervention services. Medical record review was also used to corroborate utilization data. Each visit and hospitalization was assigned an ICD-9-CM code by a trained medical record reviewer. Preventive care visits were identified by ICD-9-CM code V20.2. Injury related visits were identified by codes 800-995. External cause of injury codes were identified by codes E800-999.

An episode of injury was defined to include all visits occurring on the same date with the same or similar ICD-9CM code. Injury follow up visits, identified either by a code of V58.3, V67.5, V54.8, V66, or V54.8 or through individual chart review, were not counted as separate episodes. To classify injuries, we used a previously published framework for grouping E code mechanism/cause and manner/intent. ${ }^{11}$

\begin{tabular}{|c|c|c|c|c|c|}
\hline & \multicolumn{4}{|c|}{ Weighted \% } & \multirow[b]{2}{*}{$\begin{array}{l}\text { Mantel-Haenszel } \\
\chi^{2} \mathrm{p} \text { value }\end{array}$} \\
\hline & $\begin{array}{l}\text { Total } \\
(n=817)\end{array}$ & $\begin{array}{l}\text { Never } \\
\text { injured (67\%) }\end{array}$ & $\begin{array}{l}\text { Injured } \\
\text { once( } 26 \%)\end{array}$ & $\begin{array}{l}\text { Injured more than } \\
\text { once }(7 \%)\end{array}$ & \\
\hline \multicolumn{6}{|l|}{ Social risk factors } \\
\hline Maternal substance abuse & 3.8 & 2.8 & 4.9 & 10.2 & 0.0003 \\
\hline Mother $<18$ at time of birth & 12.2 & 11.4 & 12.5 & 20.2 & 0.04 \\
\hline Single parent & 49.5 & 45.0 & 55.1 & 72.2 & $<0.0001$ \\
\hline $\begin{array}{l}\text { Child protective services/ } \\
\text { social service }\end{array}$ & 1.5 & 0.9 & 2.7 & 3.1 & 0.01 \\
\hline $\begin{array}{l}\text { Referral/ report of abuse } \\
\text { or neglect }\end{array}$ & 2.0 & 1.5 & 2.6 & 5.3 & 0.01 \\
\hline History of family violence & 2.3 & 1.6 & 3.4 & 4.0 & 0.03 \\
\hline Caregiver mental illness & 4.9 & 4.5 & 4.2 & 11.3 & 0.06 \\
\hline \multicolumn{6}{|l|}{$\begin{array}{l}\text { Social work/case manager/ } \\
\text { EPSDT referral }\end{array}$} \\
\hline Any social risk factor & 56.4 & 51.9 & 62.5 & 77.5 & $<0.0001$ \\
\hline \multicolumn{6}{|l|}{ Number of social risk factors } \\
\hline 0 & 43.6 & 48.1 & 37.5 & 22.6 & $<0.0001$ \\
\hline 1 & 37.8 & 35.9 & 40.7 & 45.1 & \\
\hline$\geqslant 2$ & 18.6 & 16.0 & 21.8 & 32.4 & \\
\hline
\end{tabular}


Table 2 Healthcare use of study population by injury status

\begin{tabular}{|c|c|c|c|c|c|}
\hline \multirow[b]{2}{*}{ Type of visit } & \multicolumn{4}{|c|}{ Weighted mean (SD) visits per child per year } & \multirow[b]{2}{*}{$\begin{array}{l}\text { Multiple regression } \\
\text { p value }\end{array}$} \\
\hline & $\begin{array}{l}\text { Total } \\
(\mathrm{n}=817)\end{array}$ & $\begin{array}{l}\text { Never injured } \\
(67 \%)\end{array}$ & $\begin{array}{l}\text { Injured once } \\
(26 \%)\end{array}$ & Injured more than once $(7 \%)$ & \\
\hline Well child care & $2.7(1.7)$ & $2.7(1.5)$ & $2.8(2.1)$ & $2.4(1.5)$ & 0.99 \\
\hline Other non-injury primary care & $3.5(3.4)$ & $3.3(3.1)$ & $3.8(3.6)$ & $5.2(3.6)$ & $<0.0001$ \\
\hline Non-injury specialty visits & $0.2(0.9)$ & $0.2(0.9)$ & $0.2(0.8)$ & $0.3(1.1)$ & 0.51 \\
\hline Non-injury emergency department visits & $0.2(0.5)$ & $0.2(0.5)$ & $0.3(0.7)$ & $0.4(0.5)$ & $<0.0001$ \\
\hline Non-injury hospitalizations & $0.06(0.3)$ & $0.05(0.2)$ & $0.07(0.5)$ & $0.09(0.3)$ & 0.13 \\
\hline Total non-injury encounters & $6.8(4.2)$ & $6.4(3.9)$ & $7.2(4.6)$ & $8.4(4.6)$ & $<0.0001$ \\
\hline $\begin{array}{l}\text { Duration of care in DHMC using non-injury } \\
\text { visits only (years) }\end{array}$ & $2.2(1.3)$ & $2.2(1.5)$ & $2.2(0.9)$ & $2.4(0.7)$ & 0.57 \\
\hline
\end{tabular}

We conducted two separate pilot analyses to assess the completeness of DHMC claims data. Firstly, we linked DHMC claims files for the period 1995-96 with the billing claims of The Children's Hospital (TCH), the most common alternative care site for children in DHMC, to identify the proportion of children from the birth cohort who used TCH for primary care or hospitalization. Of the 1354 children in the 1993 birth cohort, $19 \%$ also received care at TCH, the majority of which was non-trauma related, specialty care. Among this subgroup of children, only $2 \%$ of primary care visits and $7 \%$ of hospitalizations took place at TCH. Secondly, as part of a survey conducted for another study, we asked parents of an underimmunized subset of the cohort to report their use of healthcare facilities other than DHMC over their child's first three years of life. Based on 414 surveys (response rate, 48\%), $10 \%$ of children had primary care visits and $6 \%$ had one or more hospitalizations outside DHMC. From these two analyses, we concluded that DHMC claims were sufficiently complete to provide a meaningful estimate of healthcare use.

\section{Data analysis}

Because only a 55\% sample of charts of non-hospitalized children were abstracted, these data were weighted in all the analyses to account for differential probability of selection. Weights were calculated based on the selection probability. Weighted results are reported.

Patients were grouped according to whether they had zero, one, or more than one injury episode. We compared sociodemographic indicators, social risk factors, and healthcare use between groups using SAS Version 8e (Cary, NC, USA). Chi-square tests and student $t$ tests were used to compare dichotomous variables and continuous variables, respectively. A $p$ value of less than 0.05 , two-tailed, was considered significant. For multivariate analyses, a $\chi^{2}$ test for trend and

\begin{tabular}{lc}
\hline Table 3 Type of injury & \\
\hline External cause & Total weighted \% \\
\hline Fall & 30.3 \\
Struck by/against & 13.3 \\
Poisoning & 7.5 \\
Cut/pierce & 6.8 \\
Fire/burn & 6.4 \\
Suffocation & 5.4 \\
Caught accidentally in/between object & 4.9 \\
Motor vehicle traffic & 2.2 \\
Bites and stings & 3.1 \\
Foreign body & 1.9 \\
Battering/maltreatment & 0.7 \\
Other specified, not elsewhere classifiable & 3.3 \\
Unknown/unspecified* & 14.3 \\
All injury† & 100.1 \\
\hline
\end{tabular}

*No external cause of injury documented in chart. tPercentages may not add up to 100 due to rounding. multiple regression were used to compare the three groups. For use of healthcare services, mean visits per child per year are presented. Analyses of healthcare use are adjusted for duration of time in the DHMC system.

\section{RESULTS}

In 1993, 2652 children were born at the Denver Health Medical Center. Figure 1 shows numbers and percentages of children excluded based on each exclusion criterion. The final study cohort included 172 hospitalized children and 645 children who were not hospitalized $(\mathrm{n}=817)$. In the cohort, $26 \%$ had 1 injury episode and $7 \%$ had $>1$ injury episode (range 2-7). Children with 0,1 , and $>1$ injury did not differ by sex, ethnicity, primary payer, or duration of care in the DHMC system. The majority of children in all groups were Hispanic $(76 \%)$ and had Medicaid (government sponsored) insurance $(68 \%)$.

Social risk factors are shown in table 1 . Children were more likely to have $\geqslant 1$ injury episodes if they had a substance abusing or adolescent mother, a single parent, a previous child protection or social services referral, or a history of family violence or mental illness in the primary caregiver. Social risk factors not found to be significant included being homeless $(p=0.27)$, having a primary caregiver other than the mother $(p=0.86)$, or having an incarcerated parent $(\mathrm{p}=0.94)$, but these conditions were rare in our population, occurring in $<3 \%$ of cases. Having any social risk factors significantly increased the risk of one or more injury episodes. Patients with multiple social risk factors had more injury episodes.

We found no association between injury episodes and the rates of well child care visits (table 2). However, children with $\geqslant 1$ injury episodes had more primary care and emergency department visits and more total non-injury encounters than did children with no injuries. A similar but non-significant trend was seen for non-injury hospitalizations.

The large majority of injuries were unintentional. External causes of injury are shown in table 3. Falls were the most common cause of injury visits, followed by being struck by or against someone or something. Fewer than $1 \%$ of injuries were documented to be from battering or maltreatment. One in seven injuries could not be classified due to inadequate documentation in the medical records.

\section{DISCUSSION}

In this retrospective cohort study of children born in an integrated public healthcare system, 33\% of the cohort had one or more injury episodes over the first three years of life that resulted in a hospitalization, or a visit to the emergency department or to a primary care clinic. Children with multiple injuries were at greater risk for having any social risk factor and having multiple social risk factors, than children with a single injury, who in turn were at greater risk for having 
social risk factors than were children with no injury. A similar relation was seen for a number of individual social risk factors. Children with multiple injury episodes also had more non-injury related primary care and emergency department visits. However, rates of well child care visits were similar among injured and uninjured children.

The large majority of injuries were unintentional, with falls being the most common cause, while intentional injuries were rare. Our results are consistent with previous studies showing falls to be the most common cause of non-fatal injury in this age group, and intentional injuries to be rare. $^{35}{ }^{12}{ }^{13}$ Although it is difficult to make direct comparisons of injury rates, as most other studies of non-fatal injury rates in children have been restricted to a single setting (for example, hospitals, emergency departments, or primary care offices), the injury rates in our study are generally consistent with previously reports. ${ }^{312} 13$

A number of studies have examined social and other risk factors for injury occurrence among children, ${ }^{14}$ as well as risk based on prior injury occurrence, ${ }^{8}{ }^{15-17}$ but few have looked at the interaction of social risk factors and recurrence. Langley et al did not find consistent differences in social or other risk factors among children with no, one, or more than one injury. ${ }^{18}$ In a study with five year follow up of a birth cohort, Bijur et al found that $12.3 \%$ of this cohort had two or more injuries which required medical advice and treatment and that males were more likely to have recurrent injuries. ${ }^{19}$ Associations between injuries and social risk factors such as social class were present but were weaker than the associations between injuries and child behavior. Results may have differed from ours because of differences in the study populations, as these studies were both based on large national cohorts, whereas we studied an urban, low income population among whom multiple social risk factors were common, and differences in methods for collecting data on social risk factors. There is little evidence from the literature about healthcare use by children with recurrent injury. In our study, children who were recurrently injured were more likely to have more non-injury related primary care and emergency department visits but not more visits for well child care. Kendrick similarly found that children who did not attend routine child health surveillance were not at an increased risk of injuries. ${ }^{20}$

Although our study did not examine injury preventive practices, a systematic review of previous research has demonstrated that injury prevention counseling in the clinical setting results in improvements in safety behaviours. ${ }^{21}$ Injury prevention counseling has been recommended in evidence based practice guidelines. ${ }^{22}$ Opportunities for injury prevention teaching and identification of families with social risk factors can be found at both injury and non-injury related medical visits.

This study has several limitations. Firstly, our study is most generalizable to similar populations of urban low income children. However, the prevalence and causes of injury in our study were similar to other studies based on national data. Secondly, medical chart review may underestimate the prevalence of maternal social risk factors, and providers may be more likely to document social risk factors among injured children. To lessen this source of bias, we extracted social risk factors from standardized forms used at all newborn and well child care visits, identified social risk factors that were documented in non-injury as well as injury related visits, and looked for risk factors during visits that occurred before as well as after an injury visit. Thirdly, we were unable to identify injuries that resulted in visits to other healthcare systems. However, our pilot analyses suggested that a large majority of children in the DHMC system receive most of their care at DHMC. Finally, we are unable to

\section{Key points}

- Injuries are the leading cause of morbidity and mortality in children aged over 1 year and are potentially preventable.

- Risk factors for injury include coming from a family with a low socioeconomic income, unemployed caregivers, or caregivers with less education. Multiply injured children appear to have more social risk factors in their families.

- Injury prevention counseling in the clinical setting for families with children has been shown to reduce unsafe practices and to increase the use of safety devices and safe behaviors.

- Children with multiple injuries are using our healthcare systems and therefore are potentially available to receive injury prevention guidance; however, their well child care attendance is no different from that of children with no injuries for which medical care was sought. Injury prevention effort should therefore be delivered during all types of visits to the healthcare system, both well child checks and acute visits.

quantify the extent to which children suffered injuries for which they sought no medical attention. It is plausible that the association between injury visits and visits for other reasons is due to a propensity of parents living in stressful situations (that is, those with more social risk factors), to bring in their children for minor illnesses, including minor trauma.

\section{CONCLUSIONS}

In an urban system of care for disadvantaged children, we found that one third of a birth cohort of children had clinical encounters for injuries, and that one in 14 had multiple injury visits during their first three years of life. Several social factors increased the risk of such visits. Children with recurrent injury visits used the healthcare system more for non-injury related visits and therefore had a greater exposure to healthcare providers. Anticipatory guidance around injury prevention can be delivered not only during well child care visits but also during the multiple other visits, both injury and non-injury related, that all children have with healthcare providers. Recognizing children with multiple injuries may also identify children and parents who would benefit from additional evaluation, interventions, and referral.

\section{ACKNOWLEDGEMENTS}

This publication was supported in part by Contract \# 97-06432 with the Colorado Department of Public Health and Environment and in part by Grant Number R49/CCR811509 from the Centers for Disease Control and Prevention. Its contents are solely the responsibility of the authors and do not necessarily represent the official views of the Centers for Disease Control and Prevention. Supported by the Colorado Injury Control Research Center, Colorado State University, Fort Collins, CO, USA.

\section{Authors' affiliations}

P A Braun, Department of Community Health Services, Denver Health, Denver, CO, USA

P A Braun, B L Beaty, C DiGuiseppi, J F Steiner, University of Colorado Health Sciences Center, Denver, CO, USA

The study was approved by the University of Colorado Multiple Institutional Review Board.

Conflicts of interest/corporate sponsorships: none. 


\section{REFERENCES}

1 Centers for Disease Control and Prevention, National Center for Injury Prevention and Control. Online at: http://cdc.gov/ncipc/osp/usmort.htm. Accessed August 20, 2003.

2 National Center for Injury Prevention and Control. Available at http:// cdc.gov/ncipc/wisqars.htm (accessed 2 February 2003).

3 Hambidge SJ, Davidson AJ, Gonzales R, et al. Epidemiology of pediatric injury-related primary care office visits in the United States. Pediatrics 2002;109:559-65.

4 Durkin MS, Davidson LL, Kuhn L, et al. Low-income neighborhoods and the risk of severe pediatric injury: a small-area analysis in northern Manhattan. Am J Public Health 1994:84:587-92.

5 Bourguet CC, McArtor RE. Unintentional injuries. Risk factors in preschool children. Am J Dis Child 1989;143:556-9.

6 Pomerantz WJ, Dowd MD, Buncher CR. Relationship between socioeconomic factors and severe childhood injuries. J Urban Health 2001;78:141-51.

7 Scholer SJ, Hickson GB, Ray WA. Sociodemographic factors identify US infants at high risk of injury mortality. Pediatrics 1999;103:1183-8.

8 Madden C, Garrett JM, Cole TB, et al. The urban epidemiology of recurrent injury: beyond age, race, and gender stereotypes. Acad Emerg Med 1997:4:772-5.

9 Horwitz SM, Morgenstern H, DiPietro L, et al. Determinants of pediatric injuries. Am J Dis Child 1988;142:605-11.

10 Muldoon JH, Neff JM, Gay JC. Profiling the health service needs of populations using diagnosis-based classification systems. J Ambul Care Manage 1997:20:1-18.

11 Recommended framework for presenting injury mortality data. MMWR Recomm Rep 1997;46:1-30.
12 Vyrostek SB, Annest Jl, Ryan GW Surveillance for fatal and nonfatal injuries-United States, 2001. MMWR 2004;53:1-57.

13 Zuckerbraun NS, Powell EC, Sheehan KM, et al. Community childhood injury surveillance: an emergency department-based model. Pediatric Emergency Care 2004:20:361-6.

14 Wazana A. Are there injury-prone children? A critical review of the literature. Can J Psychiatry 1997; 42:602-10.

15 Bijur PE, Golding J, Haslum M. Persistence of occurrence of injury: can injuries of preschool children predict injuries of school-aged children? Pediatrics 1988;82:707-12

16 Jaquess DL, Finney JW. Previous injuries and behavior problems predict children's injuries. J Pediatr Psychol 1994;19:79-89.

17 Boyce WT, Sobolewski S. Recurrent injuries in schoolchildren. Am J Dis Child 1989;143:338-42.

18 Langley J, Silva P, Williams S. A study of the relationship of 90 background, developmental, behavioral and medical factors to childhood accidents: A report from the Dunedin multidisciplinary child development study. Aust Paediatr J 1980;16:244-7.

19 Bijur PE, Stewart-Brown S, Butler N. Child behavior and accidental injury in 11,966 preschool children. Am J Dis Child 1986;140:487-92.

20 Kendrick D, West J, Wright S, et al. Does routine child health surveillance reach children most at risk of accidental injury? I Public Health Med 1995; 17:39-45.

21 DiGuiseppi C, Roberts IG. Individual-level injury prevention strategies in the clinical setting. Future Child 2000;10:53-82.

22 U.S. Preventive Services Task Force. Guide to clinical preventive services, 2nd ed. In: DiGuiseppi C, Atkins D, Woolf S, Kamerow D, eds. Baltimore, MD, Williams \& Wilkins, 1996.

\section{LACUNAE}

\section{Cost of injury}

n the United States, a report showed that half of the households in bankruptcy courts reported that illness or medical bills drove them to bankruptcy. Of interest to Injury Prevention readers, nearly a third of the households in bankruptcy reported trauma/ orthopedic/back problems. This finding indicates a perhaps undervalued benefit of preventing injuries. Further investigation of the sources of the injury (road crash, etc) would help focus injury prevention efforts on the financially debilitating injuries. To read the paper, visit http://content.healthaffairs.org/cgi/content/full/hlthaff.w5.63/DC1.

Contributed by Peter Jacobsen. 